M-1933

I. Chem. Thermodynamics $1986,18,609-618$

\title{
Thermophysics of metal alkanoates V. Heat capacities and thermodynamic properties of lithium $n$-butanoate and $\boldsymbol{n}$-hexanoate ${ }^{a}$
}

\author{
S. P. NGEYI, E. F. WESTRUM, JR.. \\ Department of Chemistry, University of Michigan, \\ Ann Arbor, Michigan 48109, U.S.A. \\ and P. FRANZOSINI $\dagger$ \\ CNR c/o Dipartimento di Chimica Fisica. \\ Università di Pavia, Viale Taramelli 16. \\ I-27I00 Pavia, Italy.
}

(Received 2 October 1985)

\begin{abstract}
The heat capacities of solid lithium $n$-butanoate and $n$-hexanoate have been investigated by adiabatic calorimetry between 5 and $350 \mathrm{~K}$. The values at $T=298.15 \mathrm{~K}$ of $C_{p . m} R$, $\left\{S_{\mathrm{m}}^{0}(T)-S_{\mathrm{m}}^{0}(0)\right\} / R,\left\{H_{\mathrm{m}}^{0}(T)-H_{\mathrm{m}}^{0}(0)\right\} / R$, and $\left\{G_{\mathrm{m}}^{0}(T)-H_{\mathrm{m}}^{0}(0)\right\} / R T$ are $18.45,20.85,3071.0 \mathrm{~K}$, and -10.546 for $n-\mathrm{CH}_{3}\left(\mathrm{CH}_{2}\right)_{2} \mathrm{CO}_{2} \mathrm{Li}$, and $25.98,27.48,4200.8 \mathrm{~K}$, and -13.387 for $n-\mathrm{CH}_{3}\left(\mathrm{CH}_{2}\right)_{4} \mathrm{CO}_{2} \mathrm{Li}$. No evidence was obtained for the occurrence in either salt of subambient discontinuous (first-order) phase transitions. Both alkanoates, however, undergo gradual (higher-order) thermodynamic transformations in the temperature region explored: possible origins of these are discussed qualitatively. Analysis of the expected "lattice" heat capacities for members of the homologous series in terms of $\mathrm{CH}_{2}$ contributions has been performed.
\end{abstract}

\section{Introduction}

We recently provided by equilibrium adiabatic calorimetry ${ }^{(1,2)}$ a complete picture, in terms of $C_{p, \mathrm{~m}} / R, \quad\left\{S_{\mathrm{m}}^{0}(T)-S_{\mathrm{m}}^{0}(0)\right\} / R, \quad\left\{H_{\mathrm{m}}^{0}(T)-H_{\mathrm{m}}^{0}(0)\right\} / R$, and $\left\{G_{\mathrm{m}}^{\mathrm{o}}(T)-H_{\mathrm{m}}^{\mathrm{o}}(0)\right\} / R T$, of the thermophysics of lithium, sodium, and potassium propanoates in the temperature range 5 to $350 \mathrm{~K}$.

Investigation has been extended to the next higher homologs for which, in general, different thermal behavior, and, in particular, changes in the fusion mechanisms are to be expected. It is known ${ }^{(3)}$ for example that, when $\mathrm{Na}$ or $\mathrm{K}$ is the cation, the so-called "chain fusion process" - associated with the transformation of the anion from its extended configuration into a (more or less) spheroidal one starts with $n_{\mathrm{C}}=4$ ( $n_{\mathrm{C}}$ : number of carbon atoms) giving rise (in this instance) to a mesomorphic liquid of the smectic type and subsequently an isotropic liquid.

"The first paper in this series is reference 7 .

+ Died 24 January 1986. 
In the lithium $n$-alkanoate family, to which belong the four homologs studied in the present (n-butanoate and $n$-hexanoate) and next ( $n$-pentanoate and $n$-heptanoate) papers of this series, changes in thermal behavior are less drastic, and the presently available information (consisting mainly of $\Delta_{\mathrm{fus}} S_{\mathrm{m}} / R$ and $\Delta_{\mathrm{trs}} S_{\mathrm{m}} / R$ obtained by one of us from d.s.c. traces recorded at $T / K \geqslant 110)^{(3,4)}$ is summarized here.

The fusion temperatures increase from methanoate $\left(n_{\mathrm{C}}=1\right)$ to propanoate $\left(n_{\mathrm{C}}=3\right)$, then decrease smoothly from $n$-butanoate $\left(n_{\mathrm{C}}=4\right)$ to $n$-hendecanoate $\left(n_{\mathrm{C}}=11\right)$, and finally remain almost constant from $n$-dodecanoate $\left(n_{\mathrm{C}}=12\right)$ to $n$-eicosanoate $\left(n_{\mathrm{C}}=20\right)$. Propanoate also exhibits fusion of a metastable form. A plot of the corresponding $\Delta_{\mathrm{fus}} S_{\mathrm{m}} / R$ values in figure 1 shows no correlation apparent among the entropies of fusion in the three lowest homologs, whereas linear correlations exist among the entropies of fusion for the homologs for which $4 \leqslant n_{\mathrm{C}} \leqslant 11\left(\Delta_{\mathrm{fus}} S_{\mathrm{m}} / R=2.681+0.388 n_{\mathrm{C}} ;\right.$ compare curve $\mathrm{A}$ in figure 1$)$, and among the entropies of fusion for those for which $12 \leqslant n_{\mathrm{C}} \leqslant 20\left(\Delta_{\mathrm{fus}} S_{\mathrm{m}} / R=4.372+0.004 n_{\mathrm{C}}\right.$; compare curve $\mathrm{B}$ in figure 1). The $\Delta_{\mathrm{fus}(\mathrm{M})} S_{\mathrm{m}} / R$ value which pertains to fusion of the metastable propanoate ${ }^{(3)}$ also falls on curve $A$, extrapolated to $n_{C}=3$. In conclusion, it can be reasonably asserted that the high-temperature stable form (Crystal I) of each of the three lowest homologs has its own mechanism of fusion, whereas metastable propanoate and homologs for which $4 \leqslant n_{\mathrm{C}} \leqslant 11$ have related fusion processes, and homologs for which $12 \leqslant n_{\mathrm{C}} \leqslant 20$ also have similar mechanisms but differ from those of the previous set.

Plastic crystals form at $400<T_{\text {trs }}<T_{\text {fus }}$ for $n_{\mathrm{C}} \geqslant 12$, but a discussion of them is unnecessary here.

Intercrystalline discontinuous (first-order) ${ }^{(5)}$ transitions occur in most homologs with $n_{\mathrm{C}}>3$ at $110 \leqslant T_{\mathrm{trs}} \leqslant 400$. The remarkable alternation in $T_{\mathrm{trs}}$, shown in the upper part of figure 2 with odd-even values of $n_{\mathrm{C}}$, is not apparent in the fusion temperatures. By extrapolation, Sanesi et $a l^{(6)}$ considered that an analogous transition might also occur at least in lithium $n$-hexanoate, although at a temperature (lower than $110 \mathrm{~K}$ ) inaccessible to their d.s.c. analysis. However, if d.s.c. $\Delta_{\mathrm{trs}} S_{\mathrm{m}} / R$ values are plotted against $n_{\mathrm{C}}$, as in the lower part of figure 2 , two distinct sets of points are obtained, relevant to the odd (curve A) and even (curve B) homologs, respectively.

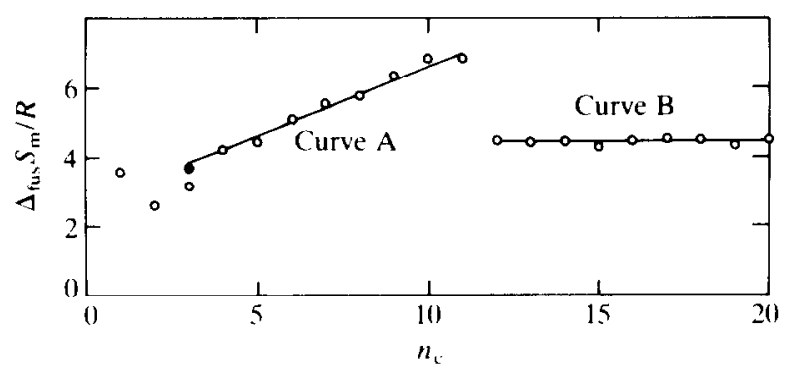

FIGURE 1. Entropies of fusion for lithium $n$-alkanoates through eicosanoate. 0 , Fusion of metastable propanoate. See text for equations. 


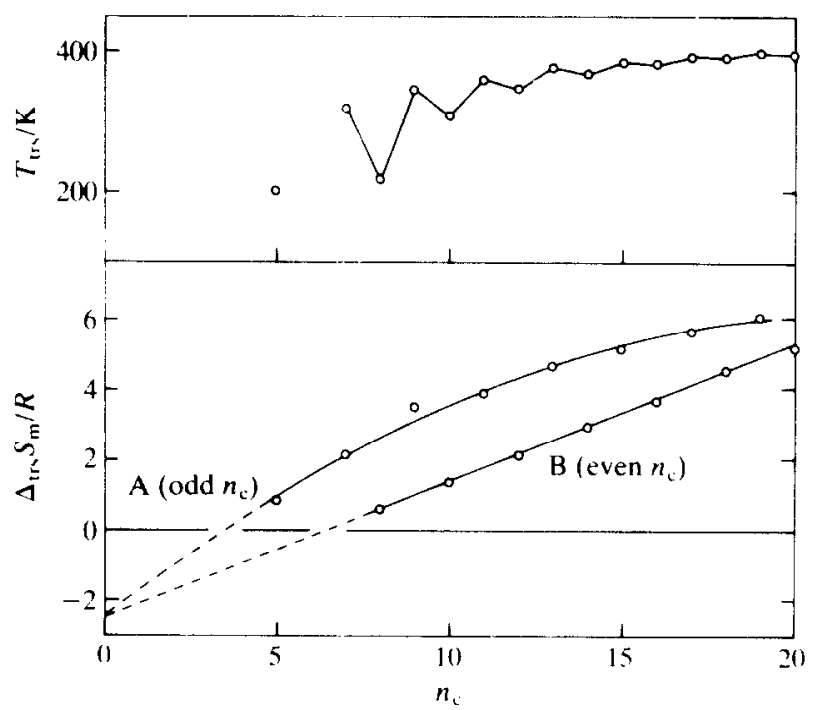

FIGURE 2. Upper part: intercrystalline transition temperatures at $T / \mathrm{K}>110$ in lithium $n$-alkanoates with $n_{C}>3$. Lower part: related entropies of transition. (See text for equations and identification of even and odd $n_{C}$ values).

Curve $B$ is satisfactorily interpolated by the linear equation: $\Delta_{\mathrm{trs}} S_{\mathrm{m}} / R$ $=-2.460+0.383\left(n_{\mathrm{c}}\right)_{\text {even }}$. For $\left(n_{\mathrm{c}}\right)_{\text {even }}<8$, the extrapolated $\Delta_{\mathrm{trs}} S_{\mathrm{m}} / R$ values are negative, which leads to the conclusion that no intercrystalline discontinuous (firstorder) transition is to be expected for either $n$-hexanoate or $n$-butanoate (studied in the present paper), although nothing can be said about the possible occurrence of gradual (higher-order) transformations in these salts. Curve A can in turn be interpolated with the parabolic equation $\Delta_{\mathrm{trs}} S_{\mathrm{m}} / R=-2.499+0.790\left(n_{\mathrm{c}}\right)_{\text {odd }}$ $-0.018\left(n_{C}\right)_{\text {odd }}^{2}$. Both curves are seen to have a common origin at $-(2.48 \pm 0.02)$.

\section{Experimental}

Lithium $n$-butanoate and $n$-hexanoate were prepared by reacting Fluka puriss ( $\geqslant 99.5$ moles per cent) $\mathrm{Li}_{2} \mathrm{CO}_{3}$ suspended in anhydrous methanol with a moderate excess ( 10 per cent) of Fluka puriss $n$-butanoic $(\geqslant 99.5)$ and $n$-hexanoic $(\geqslant 99$; tested by g.c. at the origin) acids, respectively. After refluxing under stirring for about $6 \mathrm{~h}$, cooling to room temperature, and separating of some unreacted carbonate by filtration, the solutions were concentrated to incipient crystallization in a Rotavapor device under reduced pressure. The solid alkanoates recovered after standing overnight were further purified by repeated dissolution in methanol and fractional precipitation with propan-2-ol. Both salts were finally dried to constant mass at about $380 \mathrm{~K}$ under vacuum and tested by d.s.c. analysis.

A description of the computer-operated adiabatic assembly, and of the goldplated copper calorimeter (designated W-62) employed has already been given. ${ }^{(7)}$ The calorimeter was loaded with $28.488 \mathrm{~g}$ of $\mathrm{CH}_{3}\left(\mathrm{CH}_{2}\right)_{2} \mathrm{CO}_{2} \mathrm{Li}(\triangleq 0.30294 \mathrm{~mol}$, the 
relative molar mass being $94.038 \mathrm{~g} \cdot \mathrm{mol}^{-1}$ on the basis of the IUPAC 1973 relative atomic masses), and with $24.907 \mathrm{~g}$ of $\mathrm{CH}_{3}\left(\mathrm{CH}_{2}\right)_{4} \mathrm{CO}_{2} \mathrm{Li} \quad(=0.20401 \mathrm{~mol}$; $\left.122.086 \mathrm{~g} \cdot \mathrm{mol}^{-1}\right)$. Buoyancy corrections were calculated using densities $(1.19 \pm 0.02)$ and $(1.13 \pm 0.02) \mathrm{g} \cdot \mathrm{cm}^{-3}$ for $n$-butanoate and $n$-hexanoate, respectively, obtained by Spinolo. ${ }^{\left({ }^{\prime}\right)}$

\section{Results}

The experimental $\left(C_{p, \mathrm{~m}} / R\right) \mathrm{s}$ for lithium $n$-butanoate and $n$-hexanoate are plotted in figure 3, and listed in table 1 in chronological sequence by series (designated by I. II, etc.) and within each series. The sequence of the series allows one to deduce the thermal cycles to which the sámples were submitted during measurements, and (in most cases) to obtain information on the individual temperature increments.

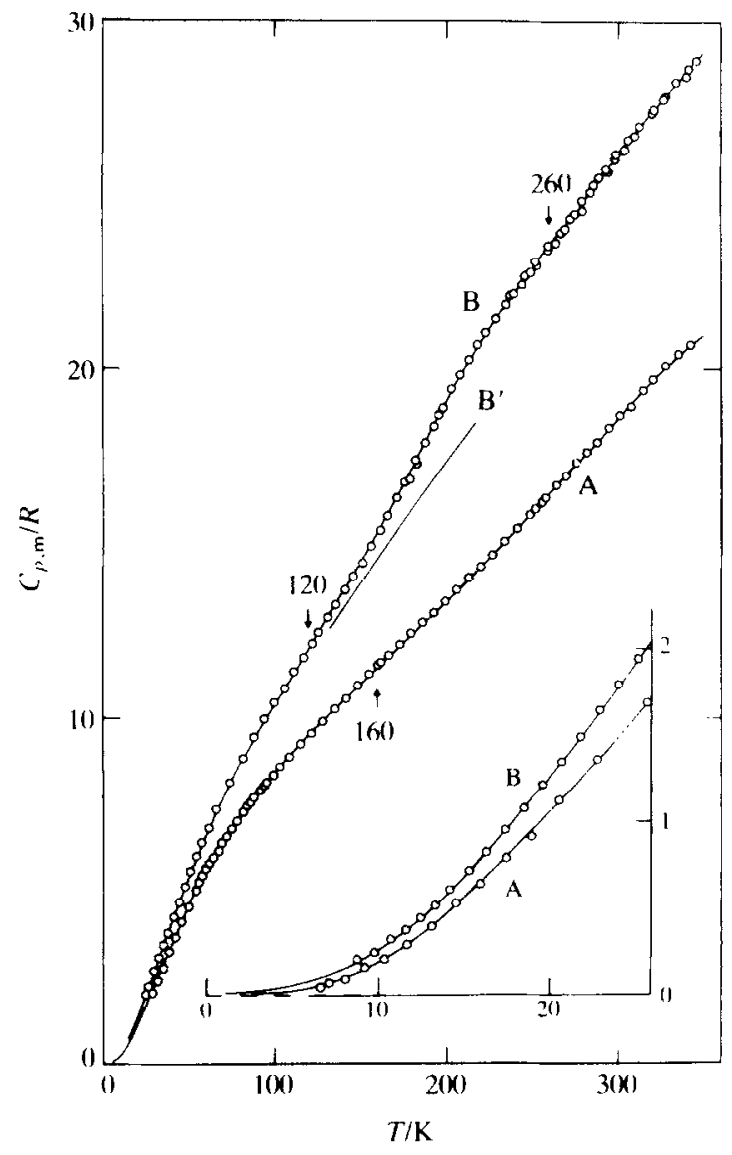

FIGURE 3. Curves $\mathrm{A}$ and B: molar heat capacities of lithium $n$-butanoate and $n$-hexanoate, respectively. up to $350 \mathrm{~K}$ (the region below $26 \mathrm{~K}$ is enlarged in the lower right-hand corner). Curve $B^{\prime}$ : a segment of the calculated (normal) "lattice" curve of lithium $n$-hexanoate, reported here to emphasize the $C_{p, m} / R$ increment due to the gradual transformations occurring in this salt above $120 \mathrm{~K}$ (for details, see text). 
TABLE I. Experimental heat capacities of lithium $n$-butanoate and n-hexanoate $\left(R=8.3144 \mathrm{~J} \cdot \mathrm{K}^{-1} \cdot \mathrm{mol}^{-1}\right)$

\begin{tabular}{|c|c|c|c|c|c|c|c|c|c|c|c|}
\hline K & $C_{p, \mathrm{~m} /} / R$ & $T / \mathbf{K}$ & $C_{p, \mathrm{~m}} / R$ & $T / \mathrm{K}$ & $C_{R, \mathrm{~m} / R}$ & $T / \mathrm{K}$ & $C_{p \cdot \mathrm{m}} / R$ & $T / \mathrm{K}$ & $C_{p, \mathrm{~m}} / R$ & $T: \mathrm{K}$ & $C_{n, \mathrm{~m}} R$ \\
\hline \multicolumn{12}{|c|}{ Lithium $n$-butanoate } \\
\hline \multicolumn{2}{|c|}{ Series I } & 5.57 & 20.402 & 241.43 & 15.399 & 141.35 & 10.527 & 8.62 & 7.730 & 15.95 & (). 642 \\
\hline & 15.873 & & 20.690 & 248.79 & & & & 4.00 & 25 & 17.45 & 0.794 \\
\hline 52.34 & 15.951 & \multicolumn{2}{|c|}{ Series II } & 256.13 & 16.170 & 154.70 & 11.210 & \multicolumn{2}{|c|}{ Series V } & 19.02 & 0.911 \\
\hline 7.75 & 16.271 & 59.90 & 11.457 & \multicolumn{2}{|c|}{ Series III } & 161.40 & 11.530 & 56.39 & 5.192 & 20.59 & 1.116 \\
\hline 263.90 & 16.620 & 165.84 & 1124 & 85.30 & 7495 & \multicolumn{2}{|c|}{ 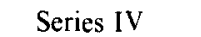 } & 58.35 & & 22.80 & 1.359 \\
\hline 270.06 & 16.883 & $=0$ & 12.0 & & 7.685 & 60.32 & 5.562 & 2.11 & & 5.72 & 1.688 \\
\hline 276.20 & 17.268 & 179.31 & 12. & & 7.897 & 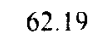 & 5.766 & Series & $s \mathrm{VI}$ & 8.63 & .032 \\
\hline 282.35 & 17.571 & & & & 8.094 & 6 & & 6.71 & & 1.62 & 380 \\
\hline & 17.851 & & & & 8.288 & & & & & & 782 \\
\hline 294 & 18.287 & & & & & & & & & & .213 \\
\hline 30 & 18.626 & & & & & & & 7 & & & 653 \\
\hline & 18.902 & & & & 9.177 & & & & & & 985 \\
\hline & 19.353 & & & & 9.539 & & & & & & 511 \\
\hline & 19.689 & & & & 9.862 & & & & & & 938 \\
\hline 37839 & 20.056 & 2 & 3 & & 0.223 & 84.32 & 4 & 18 & & 7.59 & 5.300 \\
\hline \multicolumn{12}{|c|}{ Lithium $n$-hexanoat } \\
\hline \multicolumn{2}{|c|}{ Series I } & & & 52 & 1 & 176.35 & & & & & 335 \\
\hline 176.86 & 16.823 & & 23. & & 78 & & & 05 & & 03 & 786 \\
\hline & 17.291 & & & & & & & & & & 41 \\
\hline & 17.877 & & & & .427 & 195.39 & 18.644 & Series & $s$ IV & 30 & 2.098 \\
\hline & & & & & 10.871 & Serie & III & 80 & & 45 & 260 \\
\hline & 18.866 & & & & & & & & & & 238 \\
\hline 202.96 & 19.398 & & & & 0 & & & & & 15 & 2646 \\
\hline & & & & & & & & & & & 032 \\
\hline & & & & & & & & & & .45 & 424 \\
\hline & 20.699 & & & & 90 & & & & & & 813 \\
\hline & 21.063 & & & & & & & & & & 4.232 \\
\hline 228.54 & 21.439 & & & & & & & & & & 681 \\
\hline & & & & & & & & & & & 126 \\
\hline 238.79 & 22.1 & & & & & & & & & & 60 \\
\hline & 22.402 & 45,83 & 28.8 & & & & & & & & 5.975 \\
\hline & 22.737 & & II & & & & & & & 07 & 6.394 \\
\hline 254.0 & 22.940 & 66. & & & & & & 20.67 & 1.343 & 61.54 & 6.805 \\
\hline 258.93 & 23.381 & 74.33 & 8.125 & 171.26 & 16.288 & 320.06 & 27.40 & 21.78 & 1.488 & & \\
\hline
\end{tabular}

Moreover, the smoothed $C_{p, \mathrm{~m}} / R$ values and the values of the relevant molar thermodynamic functions, calculated for a set of selected temperatures as described in reference 7, are summarized in table 2. The standard deviations in the heat capacities begin at 5 per cent at $6 \mathrm{~K}$, and decrease to 0.3 per cent at $20 \mathrm{~K}$ and to less than 0.1 per cent above $50 \mathrm{~K}$.

\section{Discussion}

It is well known ${ }^{(9)}$ that such configurational isomers as<smiles>CCCCC</smiles> 
TABLE 2. Molar thermodynamic functions of lithium $n$-butanoate and $n$-hexanoate $\left(R-8.3144 \mathrm{~J} \cdot \mathrm{K}^{-1} \cdot \mathrm{mol}^{-1}\right)$

\begin{tabular}{|c|c|c|c|c|}
\hline$T$ & $C_{p, m}$ & $S_{m}^{0}(T)-S_{m}^{0}(0)$ & $H_{\mathrm{m}}^{0}(T)-H_{\mathrm{m}}^{0}(0)$ & $G_{\mathrm{m}}^{0}(T)-H_{\mathrm{m}}^{0}(0)$ \\
\hline $\bar{K}$ & $R$ & $R$ & $R \mathrm{~K}$ & $R T$ \\
\hline \multicolumn{5}{|c|}{ Lithium $n$-butanoate } \\
\hline 0 & 0 & 0 & 0 & 0 \\
\hline 5 & 0.025 & 0.008 & 0.031 & 0.002 \\
\hline 10 & 0.188 & 0.063 & 0.475 & 0.016 \\
\hline 15 & 0.559 & 0.204 & 2.269 & 0.053 \\
\hline 20 & 1.054 & 0.430 & 6.268 & 0.117 \\
\hline 30 & 2.191 & 1.068 & 22.386 & 0.322 \\
\hline 40 & 3.374 & 1.861 & 50.22 & 0.606 \\
\hline 50 & 4.512 & 2.737 & 89.71 & 0.943 \\
\hline 60 & 5.540 & 3.654 & 140.11 & 1.318 \\
\hline 70 & 6.407 & 4.575 & 199.97 & 1.718 \\
\hline 80 & 7.139 & 5.479 & 267.80 & 2.132 \\
\hline 90 & 7.780 & 6.358 & 342.45 & 2.553 \\
\hline 100 & 8.364 & 7.208 & 423.20 & 2.976 \\
\hline 120 & 9.451 & 8.830 & 601.5 & 3.818 \\
\hline 140 & 10.482 & 10.365 & 800.9 & 4.644 \\
\hline 160 & 11.467 & 11.830 & 1020.5 & 5.452 \\
\hline 180 & 12.413 & 13.235 & 1259.3 & 6.239 \\
\hline 200 & 13.351 & 14.591 & 1516.9 & 7.007 \\
\hline 220 & 14.314 & 15.91 & 1793.5 & 7.756 \\
\hline 240 & 15.33 & 17.20 & 2089.8 & 8.490 \\
\hline 260 & 16.38 & 18.47 & 2406.8 & 9.208 \\
\hline 280 & 17.46 & 19.72 & 2745.2 & 9.914 \\
\hline 298.15 & 18.45 & 20.85 & 3071.0 & 10.546 \\
\hline 300 & 18.55 & 20.96 & 3105.2 & 10.609 \\
\hline 320 & 19.63 & 22.19 & 3487.1 & 11.295 \\
\hline 340 & 20.59 & 23.41 & 3889.5 & 11.972 \\
\hline 350 & 21.03 & 24.01 & 4097.6 & 12.307 \\
\hline \multicolumn{5}{|c|}{ Lithium $n$-hexanoate } \\
\hline 0 & 0 & 0 & 0 & 0 \\
\hline 5 & 0.045 & 0.015 & 0.056 & 0.0038 \\
\hline 10 & 0.257 & 0.099 & 0.722 & 0.0269 \\
\hline 15 & 0.683 & 0.277 & 2.989 & 0.0779 \\
\hline 20 & 1.260 & 0.550 & 7.802 & 0.160 \\
\hline 30 & 2.626 & 1.312 & 27.064 & 0.410 \\
\hline 40 & 4.070 & 2.267 & 60.60 & 0.752 \\
\hline 50 & 5.400 & 3.321 & 108.06 & 1.160 \\
\hline 60 & 6.611 & 4.414 & 168.21 & 1.611 \\
\hline 70 & 7.712 & 5.517 & 239.92 & 2.090 \\
\hline 80 & 8.707 & 6.613 & 322.10 & 2.587 \\
\hline 90 & 9.608 & 7.692 & 413.75 & 3.094 \\
\hline 100 & 10.436 & 8.747 & 514.02 & 3.607 \\
\hline 120 & 11.98 & 10.79 & 738.3 & 4.635 \\
\hline 140 & 13.55 & 12.75 & 993.3 & 5.655 \\
\hline 160 & 15.27 & 14.67 & 1281.2 & 6.662 \\
\hline 180 & 17.15 & 16.58 & 1605.2 & 7.658 \\
\hline 200 & 19.04 & 18.48 & 1967.1 & 8.645 \\
\hline 220 & 20.78 & 20.38 & 2365.6 & 9.625 \\
\hline 240 & 22.29 & 22.25 & 2796.7 & 10.600 \\
\hline 260 & 23.59 & 24.09 & 3255.7 & 11.567 \\
\hline 280 & 24.82 & 25.88 & 3739.9 & 12.526 \\
\hline 298.15 & 25.98 & 27.48 & 4200.8 & 13.387 \\
\hline 300 & 26.10 & 27.64 & 4249.0 & 13.475 \\
\hline 320 & 27.40 & 29.36 & 4784.1 & 14.414 \\
\hline 340 & 28.56 & 31.06 & 5344.1 & 15.34 \\
\hline 350 & 29.07 & 31.90 & 5632.2 & 15.80 \\
\hline
\end{tabular}


are present in gaseous $n$-butane and that the number of possible configurations increases dramatically with increasing $n_{\mathrm{c}}$. To meet potential energy requirements, however, liquefaction and crystallization do select configurations enabled to enter condensed structures so severely that most often only fully extended zig-zag chains exist in the crystal, particularly at low temperatures.

Although no X-ray diffractometric results are known so far for lithium shortchain $n$-alkanoates, it can be assumed that condensed phases of the present pair of salts behave in a way somewhat similar to that described above. Thus, for example in the case of $n$-butanoate at sufficiently low temperatures, chains are expected to fill (tail-to-tail) the space between adjacent ionic layers only in a frozen out (rigid) anti configuration:

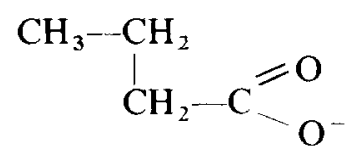

In both salts, it can further be reasonably assumed ${ }^{(10)}$ that, due to the shortness of the chains and to the strength of the electrostatic field, each group of the chain is sunk in a potential well sufficiently deep to hamper any abrupt variation of the tilt angle (i.e. the angle between the ionic layer and the axis of the chain), contrary to what occurs in higher even homologs, each of which undergoes a discontinuous (first-order) $^{(5)}$ intercrystalline transition involving this kind of variation. When temperature rises, changes of crystal packing are rather to be expected as a consequence of some kind of intramolecular orientational variation, ${ }^{(11)}$ an example of which is offered by the hindered rotational motion of the end methyl group about a $\mathrm{C}-\mathrm{C}$ bond: these are gradual rather than discontinuous thermodynamic transformations. Moreover, contributions to the overall heat capacity might also come from the progressive activation of vibrational degrees of freedom. Since vibrational (or hindered rotational) modes involve potential as well as kinetic energy, their classical (equipartition) contribution to $C_{p, \mathrm{~m}} / R \mathrm{~s}$ will obviously be equal to unity, or multiples thereof, when fully activated.

In lithium $n$-hexanoate (shown in figure 3) two distinct thermodynamic transformations develop in a continuous way between about 120 and $250 \mathrm{~K}$, and between about 260 and $330 \mathrm{~K}$, respectively. In the absence of structural information, it is difficult to infer with certainty the nature of such processes. However, the trend of the curve of $C_{p, \mathrm{~m}} / R$ against $T$ is consistent with the general statements developed above (and with expectation based on figure 2).

The shape of the lithium $n$-butanoate curve (figure 3 ) suggests in turn that a thermodynamic transformation commences near $160 \mathrm{~K}$ (i.e. at a temperature higher than for $n$-hexanoate), and approaches completion over a temperature interval larger than in $n$-hexanoate. This is consistent with the fact that, on the basis of a previous assertion, shorter anionic tails are expected to be held more rigidly by the electrostatic field.

The odd-homolog neighbors of lithium $n$-hexanoate behave differently from it (and from $n$-butanoate) although rather similarly to one another. The morphology 
of these differences and similarities will be discussed in the next paper of the present series. ${ }^{(12)}$

To obtain "lattice" curves for the lithium salts already studied i.e. propanoate, ${ }^{(2)}$ $n$-butanoate and $n$-hexanoate (this paper); and $n$-pentanoate and $n$-heptanoate $\}^{(12)}$ an attempt was made to use an approach already argued by White ${ }^{(13)}$ and utilized on long(er) alkyl chains embedded in a crystalline matrix $\left\{\left(n-\mathrm{C}_{18} \mathrm{H}_{37} \mathrm{NH}_{3}\right)_{2} \mathrm{CdCl}_{4}\right\}$. The energetics and dynamics of long hydrocarbon chains have already been studied in a variety of materials and interpreted in terms of the number $m\left(\mathrm{CH}_{2}\right)=\left(n_{\mathrm{C}}-2\right)$. of $\mathrm{CH}_{2}$ increments in the chain.

Odd and even values of $m\left(\mathrm{CH}_{2}\right)$ in the alkanes and also in the alkanoates seem to behave differently in some respects, particularly when $n_{\mathrm{C}}$ is small. With the (modest) amount of thermophysical information available to us such differences have to be neglected, along with the fact that the thermophysics of propanoate is rather different from that of the homologs with $4 \leqslant n_{\mathrm{C}} \leqslant 11$ (see Introduction). Moreover. detailed structural information on the compounds we have studied is virtually nonexistent.

None the less, the considerable discussion recently made on the magnitude and constancy of the $\mathrm{CH}_{2}$ increment ${ }^{(14,15)}$ and the method of differences utilized by White ${ }^{(13)}$ eliminate all contributions to the heat capacities other than that of the $\mathrm{CH}_{2}$ unit. Since our present results are constrained to small values of $n_{\mathbf{C}}$ we have developed by a similar approach a heat-capacity curve for our compounds which lies well within the envelope of White's calculated values (as shown in figure 4) based, with modifications, on Pitzer's hydrocarbon model. ${ }^{(16)}$ In figure 4 the dotted line represents the calculated contribution of $\mathrm{C}-\mathrm{C}$ stretch, $\mathrm{C}-\mathrm{C}$ bend, and $\mathrm{C}-\mathrm{H}$ vibrations as in reference 16 . The dashed line is the sum of the latter contributions and a highly hindered Einstein vibrational contribution for $\mathrm{CH}_{2}$ oscillations. The solid line represents the increments judged from our results on lithium compounds (with $3 \leqslant n_{\mathrm{C}} \leqslant 7$ ) and the frequencies of the alkancs rcported by Socrates. ${ }^{(17)}$

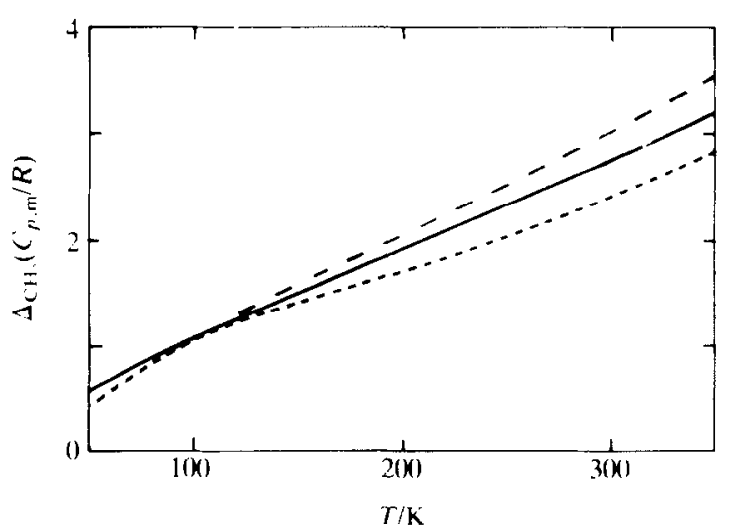

FIGURE 4. $C_{p, m} / R$ contributions from a $\mathrm{CH}_{2}$ group in a homologous alkyl series (for explanation, see FI
text). 


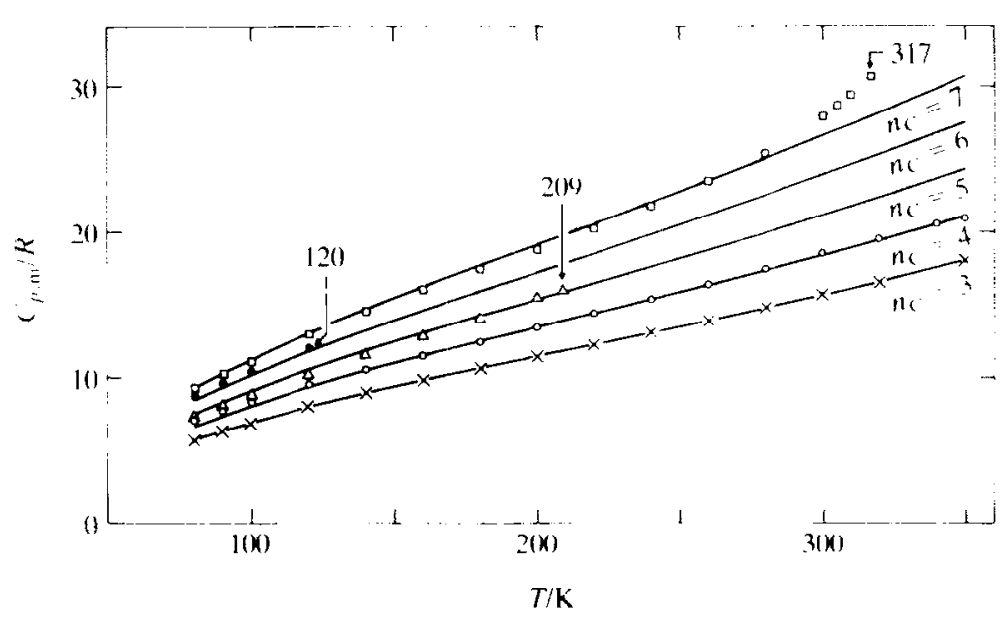

FIGURE 5. The measured (smoothed) heat capacities for $\times$, lithium propanoate; ${ }^{(2)} \bigcirc, n$-butanoate. $\triangle, n$-pentanoate, ${ }^{(12)}, n$-hexanoate: and $\square . n$-heptanoate ${ }^{(12)}$ in the temperature ranges specified in the text, and the (normal) "lattice" heat capacities (curves $n_{\mathrm{C}}=3 \ldots .7$, respectively) based on $\mathrm{CH}_{2}$ increments of figure 4.

With appropriate caveats for lack of structural knowledge, odd/even effects, small values of $n_{\mathrm{C}}$, etc., the estimated "lattice" heat capacities for lithium normal alkanoates with $3 \leqslant n_{\mathrm{C}} \leqslant 7$ are seen in figure 5 (between 80 and $350 \mathrm{~K}$ ), and appear reasonable in all respects when compared with the corresponding experimental values: between 80 and either $350 \mathrm{~K}$ (for $n$-propanoate and $n$-butanoate) or the lowest $T_{\text {trs }}$ value (i.e. $209 \mathrm{~K}$ for $n$-pentanoate, ${ }^{(12)}$ about $120 \mathrm{~K}$ for $n$-hexanoate, and $317 \mathrm{~K}$ for $n$-heptanoate). ${ }^{(12)}$

The different behavior of odd and even values of $m\left(\mathrm{CH}_{2}\right)$ was necessarily neglected, as said above, in previous calculations (compare figure 4). It is, however, to be stressed that the role played by this different behavior becomes no longer negligible when $T \rightarrow 0$. For example, below $80 \mathrm{~K}$ the calculated curves of $C_{p, \mathrm{~m}} / R$ against $T$ for lithium $n$-pentanoate and $n$-heptanoate lie increasingly higher than do the measured curves for the same substances, whereas the calculated curves for the homologs with cven values of $m\left(\mathrm{CH}_{2}\right)$ (or $\left.n_{\mathrm{C}}\right)$, i.e. $n$-butanoate and $n$-hexanoate. lie increasingly lower than the measured curves. Moreover, the sequence (from the least to the greatest $C_{p, \mathrm{~m}} / R$ at each temperature) of measured values for $C_{p, \mathrm{~m}} / R$ of lithium $n$-alkanoates with $3 \leqslant n_{\mathrm{C}} \leqslant 7$ is $n_{\mathrm{C}}=(3,4,5,6,7)$ only at $T / \mathrm{K}>80$, but becomes $n_{\mathrm{C}}=(3,5,4,7,6)$ at $T / \mathrm{K}=50$, and $n_{\mathrm{C}}=(3,5,7,4,6)$ at $T / \mathrm{K}<20$. The situation at $T / \mathrm{K}<20$ is shown in figure 6 (top).

Heat capacities are available also for three sodium $n$-alkanoates: methanoate, ${ }^{(18)}$ ethanoate. ${ }^{(7)}$ and propanoate. ${ }^{(1)}$ Here again the sequence of $C_{p, \mathrm{~m}} / R$ magnitudes (shown in figure 6 , bottom), i.e. $n_{\mathrm{C}}=(1,3,2)$ supports the above assertion that "evens" behave in a markedly different way with respect to "odds" at low temperatures. (The occurrence in the ethanoate of a transition at $21 \mathrm{~K}$ might affect the relative magnitudes of the heat capacities in this region. However, the ratios persist down to $7 \mathrm{~K}$.) 


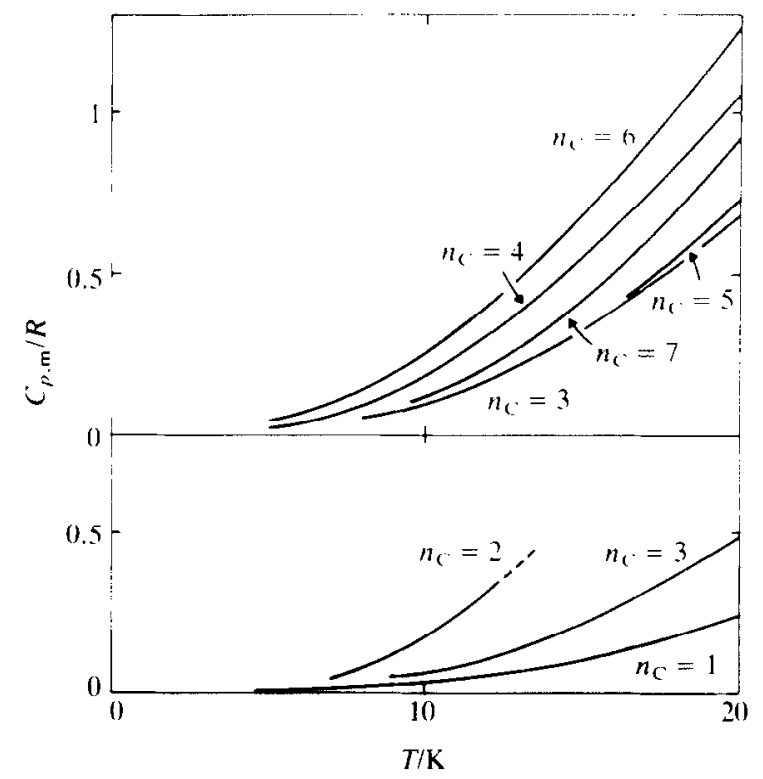

FIGURE 6. Upper part: the measured (smoothed) heat capacities for lithium propanoate (2) $n$-butanoate, $n$-pentanoate, ${ }^{(12)} n$-hexanoate, and $n$-heptanoate (curves $n_{\mathrm{C}}=3, \ldots, 7$, respectively) below $20 \mathrm{~K}$. Lower part: the measured (smoothed) heat capacities for sodium methanoate, ${ }^{(18)}$ ethanoate, ${ }^{(7)}$ and propanoate ${ }^{(1)}$ (curves $n_{\mathrm{C}}=1, \ldots, 3$, respectively) below $20 \mathrm{~K}$.

More sophisticated calculations will be possible as soon as the research program in progress will make available $C_{p, \mathrm{~m}} / R$ values for a larger number of alkali alkanoates.

\section{REFERENCES}

1. Franzosini, P.; Westrum, E. F., Jr.; Plautz, W. A. J. Chem. Thermodynamics 1983, 15, 609.

2. Franzosini, P., Westrum, E. F., Jr. J. Chem. Thermodynamics 1984, 16, 81.

3. Sanesi, M.; Cingolani, A.; Tonelli, P. L.; Franzosini, P. Thermodynamic and Transport Properties of Organic Salts. IUPAC Chemical Series, No. 28.

Franzosini, P.; Sanesi, M.: editors. Pergamon Press: Oxford. 1980, p. 29.

4. Franzosini, P.; Sanesi, M.; Cingolani, A.; Ferloni, P. Z. Naturforsch. Teil A 1980, 35, 98.

5. Skoda, W. Kolloid-Z. Polym. 1969, 234, 1128.

6. Sanesi, M.; Ferloni, P.; Franzosini, P. Z. Naturforsch. Teil A 1977, 32, 1173.

7. Franzosini, P.; Plautz, W. A.; Westrum, E. F., Jr. J. Chem. Thermodynamics 1983, 15, 445.

8. Spinolo, G., University of Pavia (Italy). Personal communication.

9. Ubbelohde, A. R. The Molten State of Matter. Wiley-Interscience: New York. 1978, p. 154.

10. Lawson, K. D.; Flautt, T. J. J. Phys. Chem. 1965, 69, 4256.

11. Ubbelohde, A. R. Pontificia Acad. Sci., Commentarii 1972, II-N. 56, 1.

12. Franzosini, P.; Ngeyi, S. P.; Westrum, E. F., Jr. J. Chem. Thermodynamics in the press

13. White, M. A. J. Chem. Phys. 1984, 31, 6100.

14. Sellers, P.; Stridh, G.; Sunner, S. J. Chem. Eng. Data 1978, 23, 250.

15. Sunner, S:; Wulffe, C. A. J. Chem. Thermodynamics 1980, 12, 505.

16. Pitzer, K. S. J. Chem. Phys. 1940, 8, 711.

17. Socrates, G. Infra-red Characteristic Group Frequencies. Wiley-Interscience: Chichester, N.Y. 1980.

18. Westrum, E. F., Jr.; Chang, S.; Levitin, N. E. J. Phys. Chem. 1960, 64, 1553. 